\title{
Design of Intelligent Lighting System based on WiFi and Arduino Single Chip Microcomputer
}

\author{
Ruini Liu \\ Xi'an FANYI University, Xi'an, 710105, China \\ 463436072@qq.com
}

\begin{abstract}
Keywords: WiFi; Arduino single chip microcomputer; Intelligent lighting; Remote control
\end{abstract}
\begin{abstract}
To solve the problem of building lighting intelligent remote control, this paper proposes an intelligent lighting control system based on WiFi and Arduino single chip microcomputer. The system with the single chip processor as the core control device, using a light sensor and infrared sensors detect light intensity within the building and the number of separately. The dynamic electromagnetic relay control lights were switched on or off according to the teaching building in light intensity and the number of people. Mobile phone client can realize remote operation of indoor lighting device by using the WiFi module for mediation. The design is simple and practical, and can easily spread to all kinds of school classroom, office building lighting intelligent remote control.
\end{abstract}

\section{Introduction}

The lighting system in colleges and universities mainly adopts the traditional artificial management way, which uses the manual switch. It has some disadvantages, such as not convenient for use, greatly wasted resources because of ever-burning lamps phenomenon, and do not conform to the requirements of the current energy saving. In view of the above disadvantages of the traditional lighting, intelligent lighting control has been becoming the current hot issues [1-5].

The intelligent lighting control mainly concentrated in the Zigbee technology [1-2] and single chip microcomputer technology [3-5] in the current. Zigbee technology has the advantages of low power consumption, strong ability in network [6], but it's shortcomings such as difficult to product development, longer development cycle, higher product cost, etc. restricted its wide application. Intelligent lighting system based on single chip microcomputer is simple, convenient to extend other functions, but it normally only to realize single machine control, therefore it cannot achieve the remote control. With the rapid development of wireless network, WiFi technology has got unprecedented development, has been applied in environmental monitoring [7], pollutant monitoring [8], intelligent greenhouse temperature control [9], etc.

This paper introduces an intelligent lighting control system design scheme uses the Arduino $\mathrm{SCM}$ as the core controller, and transmit information through wireless WiFi. The users can remote operations lighting devices in the building on the Android mobile phone client.

\section{System Architecture}

Intelligent lighting system based on $\mathrm{WiFi}$ and Arduino SCM mainly realizes the following functions:

(1) Test and display light intensity and the number of people in the classroom building.

(2) Remote operates lighting devices on the mobile client.

(3) Unified operate multiple light, and control a single lighting device separately. 


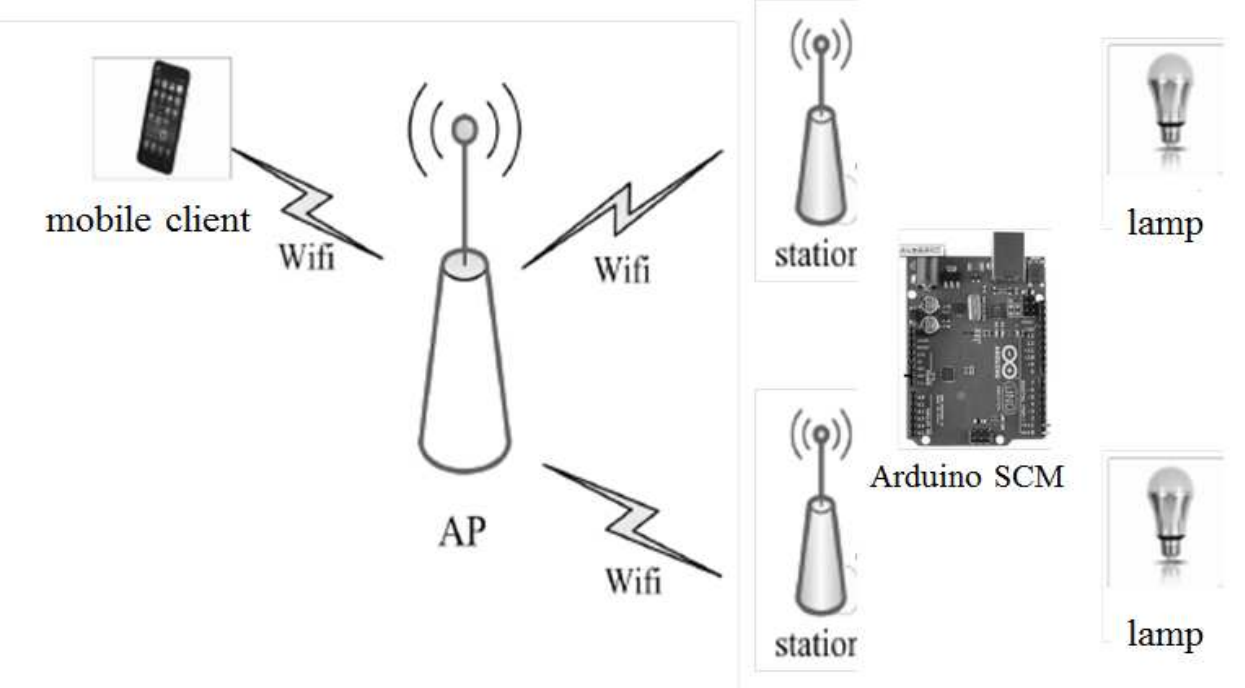

Figure1. System architecture diagram

From fig. 1, you can see, body framework of the intelligent lighting system consists of three parts: the mobile client, the AP coordinator and system terminal, the specific function analysis of each part is as follows:

Mobile phone client: system client is based on the Android operating system, which implement the user interface of the system function through constructing the Eclipse software development environment.

AP coordinator: AP coordinator is the core of the whole system communication network, realizes the $\mathrm{WiFi}$ and intelligent mobile terminal connections, by analyzing the information received.

System terminal: this part is mainly composed of WiFi Station, the single chip microcomputer and lighting. WiFi Station as wireless communications terminal equipment mainly used to implement the effective transmission of data between the clients with the mobile phone function. Single chip microcomputer as control system terminal equipment, the main implementation serial data exchange, and system terminal useful data storage and analysis, and other functions.

\section{Hardware Design}

Wireless intelligent lighting system hardware part mainly includes: wireless WiFi module, MCU module and sensor module, system structure diagram as shown in Fig. 2.

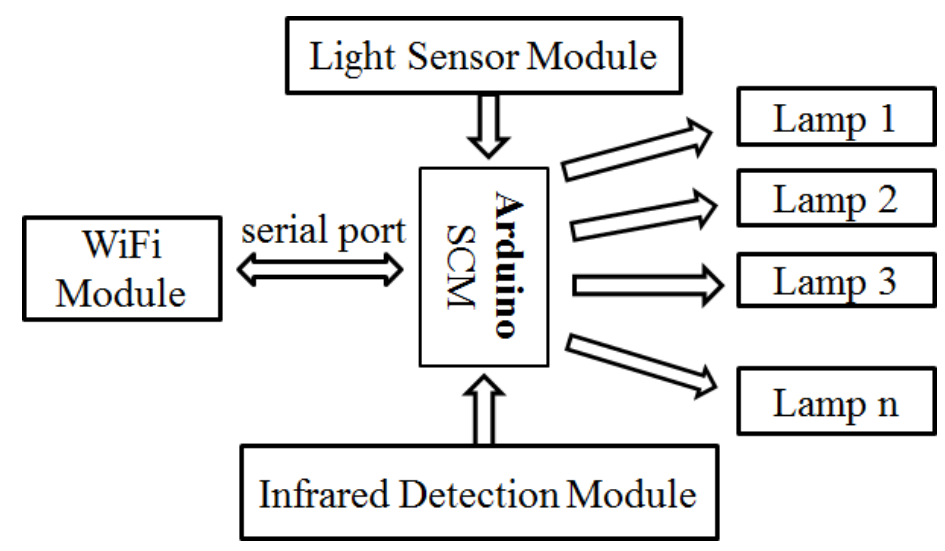

Figure 2. System structure diagram 
WiFi Module. Wireless WiFi module is used to implement system terminal communications between the client and the mobile phone. WiFi module through the asynchronous serial communication between single-chip microcomputer for data sending or receiving, the process is through the WiFi module and single-chip microcomputer with serial port. When the mobile client initiate command request signal, the signal will arrive first by WiFi network WiFi Station side, and then through the serial port to the specific signal command messages sent to the single-chip computer equipment, eventually will parse the specific command messages by single-chip microcomputer and execute the command specified function.

WiFi module of the intelligent lighting system chooses ESP8266 chip, ESP8266 is a complete and self-contained WiFi network solution, can run independently, and also can be run as a slave carry on other Host, support network modes: softAP mode, the mode can of station, softAP+ station mode, users can choose according to specific requirements.

MCU Module. Single chip microcomputer as the core of the wireless lighting control system, mainly has the following features:

1) Accept a mobile client sent via WiFi module information, judgment, the function of the information to process information received.

2) Receiving sensor module detects indoor light intensity and the number and processing.

3) Control lighting condition according the information sanded from the mobile client and sensor module testing data.

This design uses the Arduino UNO R3 microcontroller as core control unit, which using Atmel Atmega 328 microprocessor controller, with 14 digital quantity input/output ports, including six road can be used as a PWM output, analog input 6 road, a 16 MHZ crystals, support the ISP download function, compared with other same type single-chip microcomputer, the Arduino microcontroller system with the abundant resources, simple programming, module extension powerful, therefore has wide application prospect of $[10,11]$.

Sensor Module. Sensor module consists of a light sensor and infrared detection module, the main function is detecting number of people and light intensity in the teaching building in real time, and pushes the data to MCU, so that single chip microcomputer issues control commands to terminals.

The main function of light intensity detection module is for real-time accurate monitoring of the building in light intensity, this part is composed of photosensitive resistance and LM393 chips, photosensitive resistance test to different light intensity will get a different value, which have different voltage, the voltage signal to voltage comparator LM393 campus building to detect real-time light intensity. Because the Arduino UNO R3 monolithic integrated circuit to have 6 analog input channel, so the light detection circuit can be directly connected to the microcontroller, don't have to use other A/D conversion chip, simplifies the system structure.

Infrared Detection Module. Infrared detection module can to real-time detection of personnel flow situation in the classroom, is composed of infrared transmitting tube and infrared receiving tube. When infrared detect someone close to the pipe, would send a signal to amplifying circuit, the signal after amplification, transmitted to the voltage comparator, comparing with the reference voltage, to produce a high/low level, and thereby level as external counting signal of single chip microcomputer, start the single-chip microcomputer to count, the value is the number of the current in the classroom, will eventually number shown on the display.

\section{Software Design}

WiFi module is start after the system configuration initialized. Taillight nodes begin to formal work when WiFi module started. Sensor module detects the classroom building and the number of light and transmit it to $\mathrm{MCU}, \mathrm{MCU}$ processing through the wireless network transmission in mobile client, waiting for the client sends instructions: if the received information, then according to the corresponding instruction set the state of light, and return to wait for the next command, if not then continue to wait for, software flow chart as shown in Fig. 3. 
Mobile client application software design using the Eclipse, it is an open source, extensible development platform based on Java. Using the Eclipse application development need to install the ADT plugin, first it can start in Eclipse Android emulator for program debugging, etc. According to the system function requirements, development of application software interface is shown in Fig. 4. The client can display various lighting state, when the light is bright, the left small lights icon highlighting, dies icon is grey. Through to the right of the switch can adjust each lamp switch state.

It must to connect the mobile client and WiFi network when the light system works. ESP8266 choose soft AP + station mode network in this design, at this mode Android mobile phones can be used as a station connected ESP8266 soft AP interface, also can control the ESP8266 station interface connected to the Internet through a router.

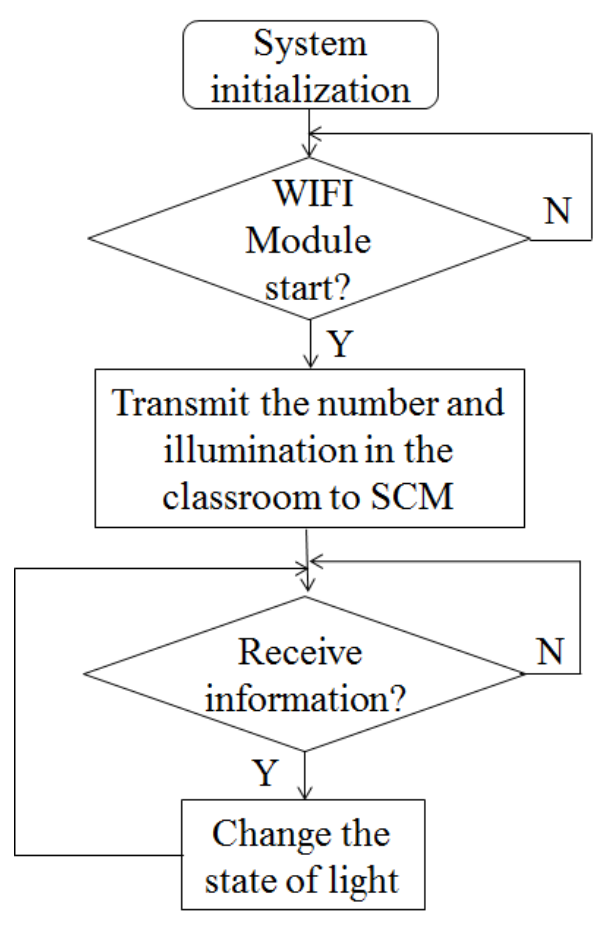

Figure 3. Program flow chart

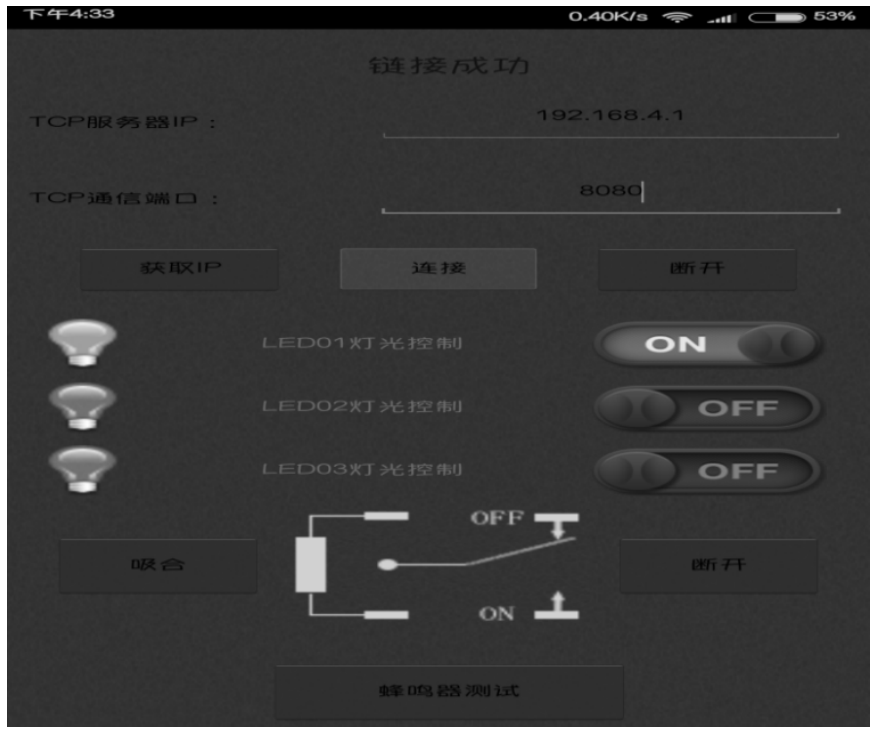

Figure 4. Mobile client interface

\section{System Test and Result Analysis}

In order to analyze the performance of the indoor lighting system based on WiFi, we tested the system function in college of engineering and technology, Xi'an Fanyi University. System function test results suggest that the system running effect good. Users can control the state of light after the mobile phones client connect with WiFi module, it's not only can control a single light, but also control multiple lights. This light system can remote wireless control the building lighting.

\section{Conclusion}

This paper proposes a teaching building lighting system designed based on WiFi and Arduino SCM. The main characteristics of the design as follows: used high-performance Arduino UNO R3 SCM as control core, to improve the system control functions. Introduced WiFi wireless communication technology in the construction of the teaching building network, in order to increase wireless communication distance and simplify the networking method. Intelligent lighting control system was designed, the system has toll collection and light collection and WiFi communication functions. Design the mobile client program, which implements the user login and real-time display of classroom lighting state, remote control, and other functions. 
For large office buildings and other places, you can use the WiFi wireless distributed system function modules, connects multiple AP to each other, in order to forming network coverage more widely.

\section{Acknowledgements}

Shaanxi province education science "choices-and graver consequences-in" planning project (SGH16H304)

\section{References}

[1] J.Y. Jin, H.Y. Wang and G.y. Jin, et al. LED intelligent lighting system based on ZigBee, J. Foreign Electronic Measurement Technology, 10 (2016) 76-82. (In Chinese)

[2] Q. Wang, Y.B. Fan. Smart home lighting system based on ZigBee technology, J. Computer Knowledge and Technology, 10 (2016) 12-13, 16. (In Chinese)

[3] Y.L. Zhang, X.P. Zhou and S.X Zhu, et al. Design and study of classroom energy-saving control system based on single chip microcomputer, J. Manufacturing Automation, 2 (2012) 103-105. (In Chinese)

[4] S.Y. Wu, J. Luo and Y.Y Wang, et al. Design of college classroom lighting energy-saving intelligent control system based on single chip, J. Electronic Design Engineering, 23(2016) 180-182. (In Chinese)

[5] Ruini Liu, Rui Liang. Design of building intelligent lighting energy saving system based on single chip, J. Computer Knowledge and Technology, 20 (2016) 224-225. (In Chinese)

[6] T. Wu, Z. Yang and L.X Zhang. Design of wireless monitoring system based on ZigBee and Android mobile phone, J. Computer Measurement and Control, 23 (2015) 809-811. (In Chinese)

[7] Y. Feng, J.H. Wang and M.K. Jiang, et al. Development of wireless indoor air pollutant monitoring device, J. Henan Science, 5 (2016) 712-715. (In Chinese)

[8] H.Y. Liu, F. Zhao and Z.H. Li, et al. Design and implementation of indoor and outdoor environment remote monitoring system based on WiFi sensor network , J. Journal of Computer Research and Development. 2 (2010) 361-365. (In Chinese)

[9] W. Jia, X.H. Xu and T. Song, et al. Design of intelligent greenhouse mobile control terminal system based on WIFI, J. Journal of Chinese Agricultural Mechanization. 5, (2015) 87-89,107. (In Chinese)

[10] K.E. Zhang, P. Wei. Remote control rescue vehicles based on the Arduino microcontroller, J. Automation and Instrumentation, 11(2016) 58-60. (In Chinese)

[11] Y.S. Bian. Microcontroller obstacle avoidance car robot based on the Arduino, J. Techniques of Automation and Applications, 1(2014) 16-19. (In Chinese) 